\title{
ESTABILIDADE E ADAPTABILIDADE DE GENÓTIPOS DE MELANCIA EM VÁRZEA TROPICAL
}

Aline Torquato Tavares ${ }^{1}$, Tiago Alves Ferreira ${ }^{2}$, Eduardo Elias Zanatta ${ }^{3}$, Irais Dolores Pascual Reyes ${ }^{2}$, Hélio Bandeira Barros ${ }^{4}$, Ildon Rodrigues do Nascimento ${ }^{4}$

\footnotetext{
${ }^{1}$ Pós-doutoranda do Programa de Pós-Graduação em Produção Vegetal, Universidade Federal do Tocantins UFT, Gurupi, Tocantins, Brasil. E-mail: alinet4t@yahoo.com.br.

${ }^{2}$ Doutorando em Produção Vegetal, Universidade Federal do Tocantins - UFT, Gurupi, Tocantins, Brasil.

${ }^{3}$ Graduando em Agronomia, Universidade Federal do Tocantins - UFT, Gurupi, Tocantins, Brasil.

${ }^{4}$ Docente do Departamento de Agronomia Universidade Federal do Tocantins - UFT, Gurupi, Tocantins, Brasil.
}

RESUMO: No Brasil, as condições edafoclimáticas são favoráveis ao cultivo da melancia e possibilitam sua produção em todo o território nacional durante todo o ano. O trabalho foi desenvolvido com o objetivo de verificar a estabilidade e adaptabilidade da produtividade de frutos de genótipos de melancia selecionados para resistência a isolados de PRSV-W (Papaya ring spot vírus - strain - $W$ ) em regiões de várzea tropical. Foram implantados quatro experimentos em condição de várzea tropical. $\mathrm{O}$ delineamento experimental utilizado foi blocos casualizados com quatro repetições. Para estudo de estabilidade e adaptabilidade, as características avaliadas foram peso médio e produtividade de frutos que foram analisados pelos métodos de Annicchiarico (1992) e Centróide ampliado por Nascimento (2009). Para complementar a caracterização dos genótipos, em 2012 também foram avaliados o conteúdo de açúcares ${ }^{\circ}$ BRIX e o formato de frutos. As linhagens MCST\#01, MCST\#04, MCST\#09 e MCST\#12 foram classificadas como de adaptabilidade geral em ambientes de várzea tropical. As linhagens MCST\#01, MCST\#03, MCST\#04, MCST\#05, MCST\#06 e MCST\#12 além de alta produtividade, possuem ${ }^{\circ}$ BRIX semelhante ao padrão comercial utilizado. As linhagens MCST\#01, MCST\#04 e MCST\#12 são promissoras para cultivo comercial ou para o desenvolvimento de híbridos indicados para várzea.

Palavras-chave: Citrullus lanatus (Thumb.). Interação genótipos x ambientes. Seleção.

\section{STABILITY AND ADAPTABILITY OF WATERMELON GENOTYPES IN TROPICAL LOWLAND}

\begin{abstract}
The Brazilian edaphoclimatic conditions are favorable to the cultivation of watermelon and enable its production throughout the national territory throughout the year. The objective of this work was to verify the stability and adaptability of fruit yield of selected watermelon genotypes for resistance to PRSV-W (Papaya ring spot virus - strain - W) isolates in tropical floodplain regions. Four experiments were implemented in tropical floodplain condition. The experimental design was randomized complete blocks with four replicates. For stability and adaptability studies, the evaluated characteristics were average weight and fruit yield, which were analyzed by the methods of Annicchiarico (1992) and Centroid extended
\end{abstract}

Cultura Agronômica, Ilha Solteira, v.26, n.3, p.362-374, 2017 
by Nascimento (2009). In addition to the characterization of the genotypes, in 2012 the content of ${ }^{\circ}$ BRIX sugars and the fruit format were also evaluated. The lines MCST\#01, MCST\#04, MCST\#09 and MCST\#12 were classified as general adaptability in tropical floodplain environments. The lines MCST\#01, MCST\#03, MCST\#04, MCST\#05, MCST\#06 and MCST\#12 in addition to high yield have ${ }^{\circ}$ BRIX similar to the commercial standard used. The lines MCST\#01, MCST\#04 and MCST\#12 are promising for commercial cultivation or for developing floodplain-suitable hybrids.

Key words: Citrullus lanatus. Genotype x environment interaction. Selection.

\section{INTRODUÇÃO}

A melancia, Citrullus lanatus (Thunb.) Matsum. \& Nakai, pertence à família Cucurbitaceae e é considerada uma das mais importantes olerícolas produzidas e comercializadas no mundo.

Na região Norte do país, o estado do Tocantins é o principal produtor com mais de nove mil hectares cultivados sob condição de várzea tropical com uso de irrigação por subsuperfície com plantios realizados nos meses de abril a julho (IBGE, 2015). Entre as espécies de vírus que acometem a cultura, está o Papaya ringspot virus strain watermelon (PRSV-W), do gênero Potyvirus que causam sintomas bastantes severos como deformações foliares, bolhosidade e necrose (AGUIAR et al., 2013; AGUIAR et al., 2015; TAVARES et al., 2014).

No Brasil, reação do tipo resistência genética a isolados brasileiros de PRSV-W foi identificado em C. lanatus var. lanatus em acessos da Nigéria (PI 595203 e PI 595201) (AZEVEDO et al., 2012; GONSALVES et al., 2010). A partir do cruzamento do acesso PI 595201 com cultivares de frutos do tipo Crimson Sweet, foram obtidas linhagens avançadas de melancia com características semelhantes ao padrão comercial Crimson Sweet, que podem ser utilizadas na obtenção de novos híbridos, com maior adaptação às condições de cultivo, em comparação com as cultivares em uso que foram desenvolvidas em locais diferentes de onde serão recomendadas.

Para recomendação de cultivares em uma região, informações de estabilidade e adaptabilidade fenotípica são de suma importância, pois permite identificar genótipos fenotipicamente mais estáveis e que respondam previsivelmente às variações ambientais (VICENTE et al., 2004), atenuando assim o efeito da interação genótipos x ambientes.

Segundo Cruz et al. (2014) considera-se que genótipos determinados conjuntamente como de adaptabilidade e estabilidade geral, ou a ambientes favoráveis ou desfavoráveis, pelo maior número de métodos, sejam mais confiáveis que apenas por um método isoladamente e a correlação entre as estimativas de adaptabilidade ou estabilidade com o uso de diferentes métodos pode contribuir para melhor predição do comportamento dos genótipos avaliados. 
O método centróide ampliado por Nascimento (2009) e Annicchiarico (1992) tem sido recomendado pela facilidade na identificação dos genótipos e possibilita explorar melhor a interação genótipos x ambientes (VASCONCELOS et al., 2015).

O trabalho foi desenvolvido com o objetivo de identificar genótipos de melancia com estabilidade e adaptabilidade para produtividade de frutos, em um grupo selecionado para resistência a isolados de PRSV-W (Papaya ring spot vírus - strain $W$ ) em condições de várzea tropical.

\section{MATERIAL E MÉTODOS}

Foram implantados quatro experimentos nos anos agrícolas de 2009, 2010, 2011 e 2012 no município de Formoso do Araguaia (170 m de altitude, $11^{\circ} 45^{\prime} \mathrm{S}, 49^{\circ} 41^{\prime} \mathrm{W}$, solo do tipo Gley Pouco Húmico). Em cada época de plantio, considerada como um ambiente, o delineamento experimental utilizado foi blocos casualizados com três repetições e foram avaliadas 12 linhagens com frutos do tipo Crimson Sweet selecionadas para resistência a PRSV-W e/ou WMV, e um híbrido utilizado como testemunha, sendo eles: MCST\#01, MCST\#02, MCST\#03, MCST\#04, MCST\#05, MCST\#06, MCST\#07, MCST\#08, MCST\#09, MCST\#10, MCST\#11, MCST\#12 e o híbrido comercial (Top Gun ${ }^{\circledR}$, pertencente à Syngenta).

A unidade experimental foi constituída de uma linha com seis plantas com espaçamento de $0,65 \mathrm{~m}$ entre plantas e 2,6 m entre linhas, sendo considerada a parcela útil as quatro plantas centrais que foram avaliadas individualmente.

O preparo do solo e a adubação de semeadura foram realizados com $650 \mathrm{Kg} \mathrm{ha}^{-1}$ de 5-25-15 e micronutrientes (padrão utilizado pelos produtores de melancia da região). Foram realizadas capinas manuais regulares conforme a necessidade da cultura e as aplicações de defensivos para o controle de pragas e doenças conforme manejo adotado pelos produtores de melancia da região.

Os frutos de cada planta da parcela experimental foram colhidos na maturidade fisiológica. A produtividade de frutos comercial foi obtida somando-se toda a produção obtida da parcela útil e dividindo-se pelo número de plantas da parcela. $\mathrm{O}$ resultado foi convertido em $\mathrm{Kg} \mathrm{ha}^{-1}$. O peso médio de frutos foi obtido em balança devidamente calibrada, obtendo valores em $\mathrm{Kg}$.

No ano de 2012 foram avaliadas também o conteúdo de açúcares ( ${ }^{\circ}$ BRIX), determinado por meio de um refratômetro de leitura direta e o índice de formato de fruto, obtido por escala de notas, em que: 1 - frutos com formato globular; 2 - frutos com formato globular achatado; 3 - frutos com formato esférico; 4 - frutos com formato cilíndrico; e 5 - frutos com formato alongado para a verificação das principais características de comercialização da fruta.

Foram realizadas as análises de variância individuais e conjunta dos ensaios. No modelo estatístico, para a análise conjunta, considerou-se fixo o efeito do genótipo e os demais efeitos aleatórios. A diferença genotípica entre os tratamentos foi verificada pelo teste de agrupamento de Scott-Knott (1974).

Cultura Agronômica, Ilha Solteira, v.26, n.3, p.362-374, 2017 
A análise de adaptabilidade e estabilidade fenotípica da produtividade de frutos dos genótipos foi feita, utilizando o programa GENES (CRUZ, 2013), pelo método Centroide Ampliado (NASCIMENTO, 2009) que consiste da comparação de valores de distância cartesiana entre os genótipos, porém acrescidos três ideótipos para representar os genótipos, sendo I, máxima adaptabilidade geral; II, máxima adaptabilidade específica a ambientes favoráveis; III, máxima adaptabilidade específica a ambientes desfavoráveis; IV, mínima adaptabilidade; V, média adaptabilidade geral; VI, média adaptabilidade específica a ambientes favoráveis e VII, média adaptabilidade específica a ambientes desfavoráveis. Para utilização desse método, os ambientes foram classificados em favoráveis e desfavoráveis, utilizando o índice ambiental como proposto por Finlay e Wilkinson (1963), ou seja, a média do ambiente menos a média geral. $\mathrm{I}_{\mathrm{j}}=\frac{1}{\mathrm{~g}} \sum_{\mathrm{i}} \mathrm{Y}_{\mathrm{ij}}-\frac{1}{\mathrm{ag}} \mathrm{Y}$ , em que: $\mathrm{Y}_{\mathrm{ij}}$ : média do genótipo i, no ambiente j; $\mathrm{Y}$ : somatória total das produtividades médias dos genótipos em todos os ambientes; a: número de ambientes e g: número de genótipos.

Após a classificação dos ambientes foram criados pontos referenciais para os ideótipos de resposta diferenciada a ambientes favoráveis e desfavoráveis, visando a classificação dos outros pontos do gráfico, considerando os valores de distância cartesiana entre os pontos e cada um dos sete ideótipos. Assim, a probabilidade é calculada utilizando o inverso da distância entre um tratamento e os seus ideótipos, pela seguinte fórmula: $\operatorname{Pd}_{(\mathrm{i}, \mathrm{j})}=\frac{\frac{1}{\mathrm{~d}_{1}}}{\sum_{\mathrm{i}=1}^{4} \frac{1}{\mathrm{~d}_{\mathrm{i}}}}$, sendo: $\operatorname{Pd}_{(\mathrm{i}, \mathrm{j})}$ : probabilidade de apresentar padrão de estabilidade semelhante ao j-ésimo centróide e $\mathrm{d}_{\mathrm{i}}$ : distância do i-ésimo ponto ao j-ésimo centróide.

Depois da classificação, procedeu-se à análise de componentes principais para obtenção dos escores utilizados na representação gráfica.

Foi feita, também utilizando o programa Genes (CRUZ, 2013), a análise de adaptabilidade e estabilidade fenotípica baseada na estatística não-paramétrica de Annicchiarico (1992). Esse método baseia-se na estimação de um índice de confiança (ou índice de recomendação) de um determinado genótipo mostrar comportamento relativamente superior. Considera-se para a obtenção desse índice: $Z_{\mathrm{ij}}=\frac{100 \mathrm{Y}_{\mathrm{ij}}}{\overline{\mathrm{Y}}_{\mathrm{j}}}, \mathrm{Y}_{\mathrm{ij}}$ : média do i-ésimo genótipo no j-ésimo ambiente e $\overline{\mathrm{Y}}_{\mathrm{j}}$ : média do j-ésimo ambiente.

A partir destes valores são obtidas as medidas de adaptabilidade e estabilidade, dadas por: $\omega_{\mathrm{i}}=\hat{\mu}_{\mathrm{i}}-\mathrm{z}(1-\alpha) \hat{\sigma}_{\mathrm{zi}}$, em que $\omega_{\mathrm{i}}$ representa o índice de confiança. Os maiores valores deste índice serão obtidos pelos genótipos que apresentaram maior média percentual $\left(\hat{\mu}_{\mathrm{i}}\right)$ e menor desvio $\widehat{\sigma}_{\mathrm{zi}}$. Estas estatísticas são obtidas conforme a seguinte descrição: Média relativa: $\hat{\mu}_{\mathrm{i}(\mathrm{g})}=\frac{\sum_{\mathrm{j}=1}^{\mathrm{a}} \mathrm{Z}_{\mathrm{ij}}}{\mathrm{a}}$, referente à média do genótipo, considerando todos os ambientes ( $\mathrm{a}=$ número de ambientes); Média dos ambientes favoráveis: $\hat{\mu}_{\mathrm{i}(\mathrm{f})}=\frac{\sum_{\mathrm{j}=1}^{\mathrm{f}} \mathrm{Z}_{\mathrm{ij}}}{\mathrm{f}}$; e Média dos ambientes desfavoráveis: $\hat{\mu}_{\mathrm{i}(\mathrm{d})}=\frac{\sum_{\mathrm{j}=1}^{\mathrm{d}} \mathrm{Z}_{\mathrm{ij}}}{\mathrm{d}}$.

Os desvios relativos são obtidos pelo desvio-padrão dos valores $\mathrm{Z}_{\mathrm{ij}}$ do i-ésimo genótipo, considerando seu comportamento em todos os ambientes $\left(\widehat{\sigma}_{\mathrm{zi}(\mathrm{g})}\right)$; desvio-padrão dos valores $\mathrm{Z}_{\mathrm{ij}}$ do 
i-ésimo genótipo, considerando seu comportamento apenas nos ambientes favoráveis $\left(\widehat{\sigma}_{\mathrm{zi}(\mathrm{f})}\right)$; desvio-padrão dos valores $\mathrm{Z}_{\mathrm{ij}}$, do i-ésimo genótipo, considerando seu comportamento apenas nos ambientes desfavoráveis $\left(\widehat{\sigma}_{\mathrm{zi}(\mathrm{d})}\right)$. O índice de recomendação é calculado pela expressão: ${ }_{\omega_{\mathrm{i}}(\mathrm{g})}=\hat{\mu}_{\mathrm{i}(\mathrm{g})}{ }^{-}$ $z(1-\alpha) \hat{\sigma}_{\mathrm{zi}(\mathrm{g})}$, considerando todos os ambientes; $\omega_{\mathrm{i}(\mathrm{f})}=\hat{\mu}_{\mathrm{i}(\mathrm{f})}-\mathrm{z}(1-\alpha) \hat{\sigma}_{\mathrm{zi}}(\mathrm{f})$, considerando os ambientes favoráveis; $\mathrm{e}_{\omega_{\mathrm{i}}(\mathrm{d})}=\hat{\mu}_{\mathrm{i}(\mathrm{d})}-\mathrm{z}(1-\alpha) \hat{\sigma}_{\mathrm{zi}}(\mathrm{d})$, considerando os ambientes desfavoráveis.

O coeficiente de confiança adotado foi de $75 \%$, ou seja, $\alpha=0,25$, sendo ainda $\mathrm{z}_{(1-\alpha)}$ : valor na distribuição normal estandardizada no qual a função de distribuição acumulada atinge o valor 1$\alpha$, com nível de significância pré-fixado pelo autor em 0,25 . Quanto maior for o índice de confiança, maior será a confiança na recomendação do cultivar.

\section{RESULTADOS E DISCUSSÃO}

Para peso médio de frutos houve diferença significativa $(\mathrm{P}>0,01)$ para genótipos, ambientes e para a interação genótipos x ambientes, o que mostra que os fatores são dependentes, ou seja, o fator ambiente influenciou da mesma maneira os genótipos para essa característica, havendo, portanto necessidade de realizar o estudo de adaptabilidade e estabilidade (Tabela 1).

Tabela 1. Resumo da análise de variância para as características peso médio de frutos $(\mathrm{Kg})$ e produtividade $\left(\mathrm{t} \mathrm{ha}^{-1}\right)$ em condição de várzea para quatro anos de avaliação. Formoso do Araguaia, 2009, 2010, 2011 e 2012.

\begin{tabular}{lccc}
\hline \multicolumn{1}{c}{ Fontes de Variação } & GL & \multicolumn{2}{c}{ Quadrados Médios } \\
\cline { 3 - 4 } & & Peso Médio de Frutos & Produtividade \\
\hline Blocos/Ambiente & 8 & 0,73199 & 70,8944 \\
Genótipos & 12 & $13,55665^{* *}$ & $480,82485^{* *}$ \\
Ambientes & 3 & $9,98805^{* *}$ & $204,87988^{\text {NS }}$ \\
Genótipos x Ambientes & 36 & $1,83074^{* *}$ & $73,86293^{* *}$ \\
Erro Médio & 96 & 0,60456 & 36,02802 \\
\hline \multicolumn{1}{c}{ Média } & & 9,20 & 24,82 \\
\multicolumn{1}{c}{ CV $(\%)$} & & 8,44 & 24,18 \\
\hline
\end{tabular}

NS $,{ }^{* *},{ }^{*}$ - Não significativo e Significativo a 1 e $5 \%$ de probabilidade, respectivamente pelo teste F.

Para a produtividade observa-se que houve diferenças significativas $(\mathrm{P}>0,05)$ para os fatores genótipos e a interação genótipos $\mathrm{x}$ ambientes, evidenciando que os genótipos são influenciados pelos ambientes. Silva et al. (2008) relatam a existência da interação genótipos x ambientes significativa em melancia, permitindo identificar genótipos de melhor adaptabilidade e maior estabilidade fenotípica.

A significância da interação entre genótipos x ambientes indica que os genótipos apresentam desempenho diferenciado frente aos ambientes. Assim faz-se necessário um estudo pormenorizado do comportamento frente a essas variações, por meio da recomendação de genótipos com estabilidade e ampla adaptabilidade (BACKES et al., 2005).

Cultura Agronômica, Ilha Solteira, v.26, n.3, p.362-374, 2017 
Tabela 2. Médias para peso médio de frutos $(\mathrm{Kg})$ de 13 genótipos de melancia em quatro anos consecutivos, Formoso do Araguaia, 2009, 2010, 2011 e 2012.

\begin{tabular}{|c|c|c|c|c|c|}
\hline \multirow{2}{*}{ Genótipos } & \multicolumn{4}{|c|}{ Anos } & \multirow{2}{*}{ Média } \\
\hline & 2009 & 2010 & 2011 & 2012 & \\
\hline MCST\#01 & $10,53 \mathrm{~A}$ & $9,07 \mathrm{~A}$ & $9,99 \mathrm{~B}$ & $9,32 \mathrm{~B}$ & $9,72 \mathrm{~B}^{1}$ \\
\hline MCST\#02 & $10,74 \mathrm{~A}$ & $10,17 \mathrm{~A}$ & $9,00 \mathrm{~B}$ & $8,33 \mathrm{~B}$ & $9,56 \mathrm{~B}$ \\
\hline MCST\#03 & $10,20 \mathrm{~A}$ & $9,63 \mathrm{~A}$ & $10,07 \mathrm{~B}$ & $9,40 \mathrm{~B}$ & $9,82 \mathrm{~B}$ \\
\hline MCST\#04 & $10,61 \mathrm{~A}$ & $10,04 \mathrm{~A}$ & $10,16 \mathrm{~B}$ & $9,49 \mathrm{~B}$ & $10,08 \mathrm{~B}$ \\
\hline MCST\#05 & $7,53 \mathrm{~B}$ & $6,96 \mathrm{~B}$ & $10,45 \mathrm{~B}$ & $9,78 \mathrm{~B}$ & $8,68 \mathrm{C}$ \\
\hline MCST\#06 & $8,03 \mathrm{~B}$ & $7,46 \mathrm{~B}$ & $9,20 \mathrm{~B}$ & $8,53 \mathrm{~B}$ & $8,30 \mathrm{C}$ \\
\hline MCST\#07 & $7,80 \mathrm{~B}$ & $7,23 \mathrm{~B}$ & $9,13 \mathrm{~B}$ & $8,46 \mathrm{~B}$ & $8,15 \mathrm{C}$ \\
\hline MCST\#08 & 7,59 B & $7,02 \mathrm{~B}$ & $8,25 \mathrm{~B}$ & 7,58 B & $7,61 \mathrm{D}$ \\
\hline MCST\#09 & $10,18 \mathrm{~A}$ & $9,61 \mathrm{~A}$ & $9,45 \mathrm{~B}$ & $8,78 \mathrm{~B}$ & $9,51 \mathrm{~B}$ \\
\hline MCST\#10 & 7,81 B & $7,24 \mathrm{~B}$ & $9,47 \mathrm{~B}$ & $8,80 \mathrm{~B}$ & $8,33 \mathrm{C}$ \\
\hline MCST\#11 & 7,74 B & 7,17 B & $9,89 \mathrm{~B}$ & $9,22 \mathrm{~B}$ & $8,50 \mathrm{C}$ \\
\hline MCST\#12 & $10,11 \mathrm{~A}$ & $9,98 \mathrm{~A}$ & $9,96 \mathrm{~B}$ & $9,29 \mathrm{~B}$ & $9,83 \mathrm{~B}$ \\
\hline Top Gun ${ }^{\circledR}$ & $11,29 \mathrm{~A}$ & $10,13 \mathrm{~A}$ & $12,75 \mathrm{~A}$ & $12,07 \mathrm{~A}$ & $11,56 \mathrm{~A}$ \\
\hline
\end{tabular}

${ }^{1}$ Médias seguidas pela mesma letra maiúscula na coluna pertencem ao mesmo grupo pelo teste de agrupamento Scott-Knott (1974) ( $\mathrm{p}=0,05)$.

Na média geral, a linhagem MCST\#04 teve maior peso médio de frutos depois da testemunha, com 10,08 Kg (Tabela 2). Outras cinco linhagens (MCST\#01, MCST\#02, MCST\#03, MCST\#09 e MCST\#12) tiveram médias estatisticamente iguais a esse material.

Algumas linhagens tiveram pesos variando de 6 a $8 \mathrm{Kg}$, mas dependendo do mercado seria uma característica interessante, pois segundo Milanez (2015), as tendências recentes dos mercados interno e externo são por frutos próximos de $6,0 \mathrm{Kg}$. Porém segundo relatos dos próprios produtores da região, os consumidores da região Centro-Sul do país apreciam frutos maiores, com peso médio variando de 10 até $20 \mathrm{Kg}$.

Conforme Tabela 3, verifica-se que a produtividade média das linhagens variou de 18, $39 \mathrm{t}$ $\mathrm{ha}^{-1}$ (MCST\#07) a 36, $59 \mathrm{t} \mathrm{ha}^{-1}$ (Top Gun). Sobre esse aspecto, somente as linhagens MCST\#01, MCST\#02, MCST\#03 e MCST\#04 foram estatisticamente semelhantes à testemunha, alcançando valores bem próximos à média das principais regiões produtoras do estado que é de 30 t ha $^{-1}$ (SANTOS et al., 2010).

A maior produtividade foi da linhagem MCST\#02 (43,54 $\left.\mathrm{t} \mathrm{ha}^{-1}\right)$ no ano de 2012, sendo superior ao híbrido utilizado como testemunha $\left(39,76 \mathrm{t} \mathrm{ha}^{-1}\right)$. Porém, na média geral essa linhagem juntamente com a MCST\#01, MCST\#03 e MCST\#04 não diferiu da testemunha, apresentando as melhores médias, com o restante tendo produtividades inferiores. As cultivares de melancia que têm sido desenvolvidas visam entre outras características, altas produtividades e boas características comerciais do fruto que incluem o peso final do produto, garantindo assim um melhor preço (BOYHAN et al., 2015).

Cultura Agronômica, Ilha Solteira, v.26, n.3, p.362-374, 2017 
Tabela 3. Médias para produtividade $\left(\mathrm{t} \mathrm{ha}^{-1}\right)$ em treze genótipos de melancia em quatro anos consecutivos de avaliação, Formoso do Araguaia, 2009, 2010, 2011 e 2012.

\begin{tabular}{cccccc}
\hline \multirow{2}{*}{ Genótipos } & \multicolumn{5}{c}{ Anos } \\
\cline { 2 - 5 } & 20091 & 2010 & 2011 & 2012 & Média \\
\hline MCST\#01 & $28,42 \mathrm{~B}$ & $30,42 \mathrm{~A}$ & $25,58 \mathrm{~B}$ & $26,88 \mathrm{~B}$ & $27,82 \mathrm{~A}$ \\
MCST\#02 & $40,84 \mathrm{~A}$ & $27,13 \mathrm{~A}$ & $19,73 \mathrm{~B}$ & $43,54 \mathrm{~A}$ & $32,81 \mathrm{~A}$ \\
MCST\#03 & $35,37 \mathrm{~A}$ & $32,28 \mathrm{~A}$ & $26,03 \mathrm{~B}$ & $38,07 \mathrm{~A}$ & $32,94 \mathrm{~A}$ \\
MCST\#04 & $30,43 \mathrm{~B}$ & $25,26 \mathrm{~A}$ & $26,60 \mathrm{~B}$ & $33,13 \mathrm{~A}$ & $28,86 \mathrm{~A}$ \\
MCST\#05 & $15,34 \mathrm{C}$ & $13,17 \mathrm{~B}$ & $28,30 \mathrm{~B}$ & $18,04 \mathrm{~B}$ & $18,71 \mathrm{~B}$ \\
MCST\#06 & $17,45 \mathrm{C}$ & $21,95 \mathrm{~B}$ & $20,90 \mathrm{~B}$ & $20,15 \mathrm{~B}$ & $20,11 \mathrm{~B}$ \\
MCST\#07 & $17,53 \mathrm{C}$ & $15,32 \mathrm{~B}$ & $20,51 \mathrm{~B}$ & $20,23 \mathrm{~B}$ & $18,39 \mathrm{~B}$ \\
MCST\#08 & $20,49 \mathrm{C}$ & $19,51 \mathrm{~B}$ & $15,28 \mathrm{~B}$ & $23,19 \mathrm{~B}$ & $19,62 \mathrm{~B}$ \\
MCST\#09 & $26,68 \mathrm{~B}$ & $20,02 \mathrm{~B}$ & $22,40 \mathrm{~B}$ & $23,86 \mathrm{~B}$ & $23,24 \mathrm{~B}$ \\
MCST\#10 & $15,33 \mathrm{C}$ & $16,01 \mathrm{~B}$ & $22,52 \mathrm{~B}$ & $26,11 \mathrm{~B}$ & $19,99 \mathrm{~B}$ \\
MCST\#11 & $15,04 \mathrm{C}$ & $15,04 \mathrm{~B}$ & $24,98 \mathrm{~B}$ & $21,02 \mathrm{~B}$ & $19,02 \mathrm{~B}$ \\
MCST\#12 & $29,57 \mathrm{~B}$ & $16,10 \mathrm{~B}$ & $25,41 \mathrm{~B}$ & $27,0 \mathrm{~B}$ & $24,52 \mathrm{~B}$ \\
Top Gun $^{\circledR}$ & $28,42 \mathrm{~B}$ & $36,02 \mathrm{~A}$ & $41,88 \mathrm{~A}$ & $39,76 \mathrm{~A}$ & $36,59 \mathrm{~A}$ \\
\hline
\end{tabular}

${ }^{1}$ Médias seguidas pela mesma letra maiúscula na coluna pertencem ao mesmo grupo pelo teste de agrupamento Scott-Knott (1974) $(\mathrm{p}=0,05)$.

Tabela 4. Produtividade $\left(\mathrm{t} \mathrm{ha}{ }^{-1}\right)$ e classificação dos genótipos de melancia nos sete grupos caracterizados pelos centroides (NASCIMENTO et al., 2009) em Formoso do Araguaia, 2009, 2010, 2011 e 2012.

\begin{tabular}{cccccccccc}
\hline \multicolumn{10}{c}{ Centróide } \\
\hline Genótipos & Média $^{1}$ & Grupo & P(I) & P(II) & P(III) & P (IV) & P(V) & P(VI) & P(VII) \\
\hline MCST\#01 & 27,82A & V & 0,1021 & 0,094 & 0,1198 & 0,1073 & 0,3018 & 0,1453 & 0,1297 \\
MCST\#02 & 32,81A & VI & 0,1587 & 0,1277 & 0,1085 & 0,0968 & 0,1604 & 0,2155 & 0,1324 \\
MCST\#03 & 32,94A & VI & 0,1717 & 0,1018 & 0,1173 & 0,086 & 0,172 & 0,1966 & 0,1545 \\
MCST\#04 & 28,86A & V & 0,1055 & 0,1008 & 0,0959 & 0,0923 & 0,2897 & 0,2019 & 0,1138 \\
MCST\#05 & 18,71B & IV & 0,0791 & 0,1238 & 0,0962 & 0,2721 & 0,213 & 0,1228 & 0,093 \\
MCST\#06 & 20,11B & IV & 0,0703 & 0,1137 & 0,0848 & 0,2681 & 0,2621 & 0,1181 & 0,0829 \\
MCST\#07 & 18,39B & IV & 0,0586 & 0,108 & 0,0688 & 0,3973 & 0,1984 & 0,1014 & 0,0676 \\
MCST\#08 & 19,62B & IV & 0,0664 & 0,1283 & 0,0749 & 0,2875 & 0,2447 & 0,1231 & 0,0751 \\
MCST\#09 & 23,24B & V & 0,0658 & 0,924 & 0,078 & 0,1408 & 0,4291 & 0,115 & 0,0789 \\
MCST\#10 & 19,99B & IV & 0,0682 & 0,1485 & 0,0734 & 0,2529 & 0,2459 & 0,1361 & 0,075 \\
MCST\#11 & 19,02B & IV & 0,0705 & 0,125 & 0,0821 & 0,298 & 0,2229 & 0,1204 & 0,0811 \\
MCST\#12 & 24,52B & V & 0,0821 & 0,1099 & 0,0907 & 0,1337 & 0,3417 & 0,1467 & 0,0951 \\
Top Gun ${ }^{\circledR}$ & 36,59A & I & 0,2535 & 0,0853 & 0,1297 & 0,0743 & 0,1266 & 0,1416 & 0,189 \\
\hline
\end{tabular}

${ }^{1}$ Médias seguidas pela mesma letra maiúscula na coluna pertencem ao mesmo grupo pelo teste de agrupamento Scott-Knott (1974) $(\mathrm{p}=0,05)$.

I, máxima adaptabilidade geral; II, máxima adaptabilidade específica a ambientes favoráveis; III, máxima adaptabilidade específica a ambientes desfavoráveis; IV, mínima adaptabilidade; V, média adaptabilidade geral; VI, média 
adaptabilidade específica a ambientes favoráveis; VII, média adaptabilidade específica a ambientes desfavoráveis e a probabilidade associada a sua classificação.

Na classificação dos genótipos quanto à produtividade, foi observada a formação de quatro grupos (Tabela 4), sendo o primeiro (I) formado pelo híbrido Top Gun, apresentando adaptabilidade geral, o segundo grupo (IV) representado pelas linhagens MCST\#05, 6-MCST\#06, MCST\#07, MCST\#08, MCST\#10 e MCST\#11, indicando baixo desempenho, independentemente do ambiente, classificados como pouco adaptadas, possuindo médias que variaram de 18,39 a 20,11 t $\mathrm{ha}^{-1}$. O terceiro grupo (VI) composto pelas linhagens MCST\#02 e MCST\#03, tiveram médias de 32,81 e 32,94 t ha ${ }^{-1}$, respectivamente, e foram classificados como de adaptabilidade média a ambientes favoráveis. No quarto e último grupo (V) estão as demais, MCST\#01, MCST\#04, MCST\#09 e MCST\#12, consideradas como de média adaptabilidade geral e com produtividades variando de 23,24 a 28,86 tha ${ }^{-1}$, sendo fortes candidatas para a seleção no programa.

Na Figura 1 percebe-se, pela seta à direita formada, que os genótipos mais próximos à ponta da seta são os mais produtivos e os mais próximos à base da seta, menos produtivos. O método do centróide tem sido empregado na análise de adaptabilidade em diferentes culturas como eucaliptus (ROCHA et al., 2005), soja (PELUZIO et al., 2008) e alfafa (VASCONCELOS et al., 2011), por ser de simples visualização e compreensão.

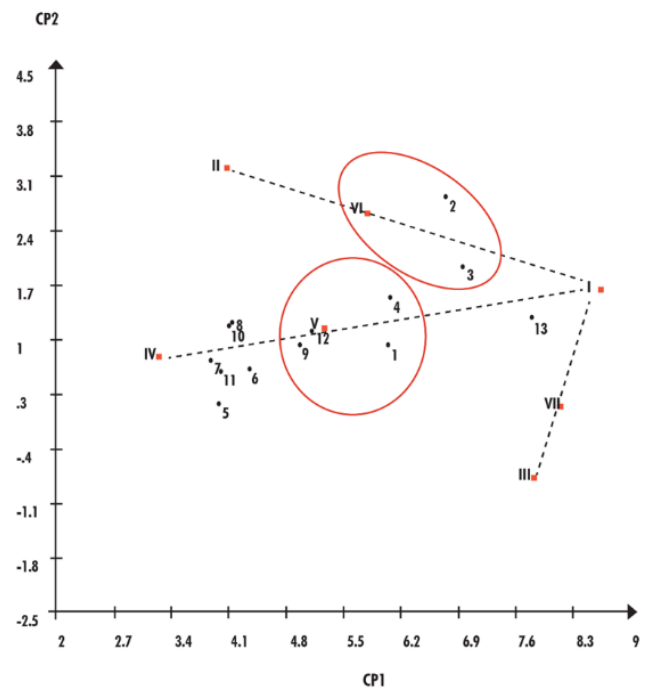

Os sete pontos numerados com algarismos romanos representam os ideótipos. I, máxima adaptabilidade geral; II, máxima adaptabilidade específica a ambientes favoráveis; III, máxima adaptabilidade específica a ambientes desfavoráveis; IV, mínima adaptabilidade; V, média adaptabilidade geral; VI, média adaptabilidade específica a ambientes favoráveis; VII, média adaptabilidade específica a ambientes desfavoráveis. CP1, componente principal 1; CP2, componente principal 2. 1-MCST\#01, 2-MCST\#02, 3-MCST\#03, 4-MCST\#04, 5-MCST\#05, 6-MCST\#06, 7-MCST\#07, 8-MCST\#08, 9-MCST\#09, 10-MCST\#10, 11-MCST\#11, 12-MCST\#12 e 13- híbrido comercial (Top Gun ${ }^{\circledR}$, pertencente à Syngenta).

Figura 1. Dispersão gráfica dos dois primeiros componentes principais dos 13 genótipos de melancia, para a variável produtividade em 4 ambientes (2009/2012).

O Índice de confiança $W_{\mathrm{i}}$ (geral e desfavorável) (Tabela 5) é apresentado pelo método de Annicchiarico (1992). Observa-se que os genótipos que apresentaram índices de confiança superiores a 100, tanto para ambientes gerais quanto para desfavoráveis, além do híbrido Top Gun, Cultura Agronômica, Ilha Solteira, v.26, n.3, p.362-374, 2017 
foram MCST\#01, MCST\#02, MCST\#03 e 4-MCST\#04. Neste método a principal vantagem está no fato de que a seleção de determinada cultivar para os agricultores é feita considerando-se o risco da mesma ter desempenho inferior a um padrão previamente escolhido que geralmente é a cultivar com maior uso em determinada região de cultivo. Nesse caso, o padrão é a média geral das cultivares avaliadas, de forma que quanto maior for o índice de confiança de uma determinada cultivar, menor será a probabilidade de insucesso desse material. Esse é o objetivo principal dos produtores na escolha da cultivar a ser adquirida (ELIAS et al., 2005).

Tabela 5. Índice de confiança $W_{\mathrm{i}}$ (geral e desfavorável) pelo método de Annicchiarico (1992) e o índice ambiental e classificação dos ambientes para as médias de produtividade. Formoso do Araguaia, 2009, 2010, 2011 e 2012.

\begin{tabular}{|c|c|c|c|c|c|}
\hline \multicolumn{6}{|c|}{ Produtividade } \\
\hline Genótipos & Wi Geral & Wi desf. & & & \\
\hline MCST\#01 & 108,39 & 114,05 & & & \\
\hline MCST\#02 & 120,54 & 110,94 & & & \\
\hline MCST\#03 & 127,83 & 125,37 & & & \\
\hline MCST\#04 & 114,31 & 112,96 & & & \\
\hline MCST\#05 & 68,10 & 70,24 & Ambiente & Média & Índice $(\mathrm{Ij})$ \\
\hline MCST\#06 & 78,19 & 80,96 & 2009 & 24,70 & $-0,11$ \\
\hline MCST\#07 & 72,30 & 72,33 & 2010 & 22,17 & $-2,64$ \\
\hline MCST\#08 & 75,95 & 73,90 & 2011 & 24,62 & $-0,19$ \\
\hline MCST\#09 & 91,13 & 93,67 & 2012 & 27,77 & 2,95 \\
\hline MCST\#10 & 75,73 & 71,16 & & & \\
\hline MCST\#11 & 71,61 & 70,77 & & & \\
\hline MCST\#12 & 92,85 & 91,97 & & & \\
\hline Top Gun $^{\circledR}$ & 141,37 & 141,56 & & & \\
\hline
\end{tabular}

Nas duas metodologias avaliadas neste trabalho, as diferenças encontradas em relação ao genótipo ideal são semelhantes, onde a média de seleção foi de 3 a 4 materiais com características desejáveis no programa de melhoramento. Vasconcelos et al. (2015) avaliando produtividade, adaptabilidade e estabilidade de grãos de soja, constataram que os métodos do Centróide e Annicchiarico foram coerentes entre si e possibilitaram indicar os mesmos genótipos de melhores comportamentos.

Para o conteúdo de açúcares ( $\left.{ }^{\circ} \mathrm{BRIX}\right)$ a linhagem MCST\#03 (Tabela 6) teve média superior ao da testemunha $(11,18)$, porém não estatisticamente diferente. $\mathrm{O}{ }^{\circ} \mathrm{BRIX}$ do fruto é importante porque é um dos principais fatores que definem a qualidade organoléptica do mesmo. Sobre esse aspecto, os valores observados como satisfatório para o mercado deve ser superior a 10 (Barros et al., 2012).

Apenas a linhagem MCST\#10 teve valor bem abaixo do exigido pelo mercado (7,51). Para Jie et al. (2013), o teor de sólidos solúveis é a característica de maior importância, que determina a qualidade comercial da melancia e também a aceitação pelo consumidor. Carmo 
et al. (2015) avaliando cultivares de melancia também encontraram valores similares aos observados nesse trabalho, com valores variando de 8 a $11^{\circ}$ BRIX.

Tabela 6. Médias do conteúdo de açúcares ( $\left.{ }^{\circ} \mathrm{BRIX}\right)$ e formato de fruto (FF) de 13 genótipos de melancia. Formoso do Araguaia, 2012.

\begin{tabular}{|c|c|c|}
\hline Genótipos & ${ }^{\circ}$ BRIX & Formato do fruto (FF) \\
\hline MCST\#01 & $9,78 \mathrm{~A}$ & 3 - Esférico \\
\hline MCST\#02 & $9,10 \mathrm{~B}$ & 3 - Esférico \\
\hline MCST\#03 & $11,18 \mathrm{~A}$ & 3 - Esférico \\
\hline MCST\#04 & $9,85 \mathrm{~A}$ & 3 - Esférico \\
\hline MCST\#05 & $10,35 \mathrm{~A}$ & 3 - Esférico \\
\hline MCST\#06 & $9,51 \mathrm{~A}$ & 3 - Esférico \\
\hline MCST\#07 & $8,01 \mathrm{~B}$ & 3 - Esférico \\
\hline MCST\#08 & $8,57 \mathrm{~B}$ & 3 - Esférico \\
\hline MCST\#09 & $8,68 \mathrm{~B}$ & 3 - Esférico \\
\hline MCST\#10 & 7,51 B & 3 - Esférico \\
\hline MCST\#11 & $8,18 \mathrm{~B}$ & 3 - Esférico \\
\hline MCST\#12 & $10,46 \mathrm{~A}$ & 3 - Esférico \\
\hline Top Gun ${ }^{\circledR}$ & $11,01 \mathrm{~A}$ & 3 - Esférico \\
\hline
\end{tabular}

${ }^{1}$ Médias seguidas pela mesma letra maiúscula na coluna pertencem ao mesmo grupo pelo teste de agrupamento Scott-Knott (1974) $(\mathrm{p}=0,05)$.

Quanto ao índice de formato de fruto, todos os genótipos apresentaram nota 3 que confere formato esférico ou arredondado, o que é desejável já que essas linhagens foram selecionadas para produzir frutos semelhantes ao padrão fenotípico do grupo, cultivar Crimson Sweet, mais cultivada no país, tanto pela sua aceitabilidade de mercado quanto pela sua adaptação em todas as regiões brasileiras, possibilitando o seu cultivo praticamente em todas as épocas do ano.

\section{CONCLUSÃO}

As linhagens de melancia MCST\#01, MCST\#04, MCST\#09 e MCST\#12 foram classificadas como de adaptabilidade geral em ambientes de várzea do estado do Tocantins.

As linhagens MCST\#01, MCST\#03, MCST\#04, MCST\#05, MCST\#06 e MCST\#12 além de alta produtividade, possuem ${ }^{\circ}$ BRIX semelhante ao padrão comercial Top Gun.

As linhagens MCST\#01, MCST\#04, e MCST\#12 são promissoras para cultivo comercial ou para o desenvolvimento de híbridos indicados para várzea no estado do Tocantins.

\section{AGRADECIMENTOS}

Ao CNPq, pelo auxílio financeiro, CAPES pela bolsa e auxílio financeiro e a Universidade Federal do Tocantins - UFT.

Cultura Agronômica, Ilha Solteira, v.26, n.3, p.362-374, 2017 


\section{REFERÊNCIAS BIBLIOGRÁFICAS}

AGUIAR, W. S.; EVANGELISTA, M. P.; RAMOS, A. C. C.; PASCOAL, P. V.; BARROS, H. B.; SANTOS, M. M. Danos e sintomatologia de vírus associado à cultura da melancia no estado do Tocantins. Bioscence Journal, Uberlândia, v. 29, n. 1, p.1632-1639, 2013.

AGUIAR, R. W. S., RODRIGUES, A., PORTELLA, A. C. F.; LOPES, M. M., LIMA, M. F., RESENDE, R. O. e NAGATA, T. Serological Identification of Virus in Watermelon Production Fields in the Tocantins State. Brazilian Archives of Biology and Technology, Curitiba, v. 1, n. 2, p.1-6, 2015.

ANNICCHIARICO, P. Cultivar adaptation and recommendation from alfafa trialsin Northern Italy. Journal of Genetics and Plant Breeding, New Delhi, v. 4, n. 3, p.269-278, 1992.

AZEVEDO, S. M.; MALUF, W. R.; FARIA, M. V.; RESENDE, J. T. V.; MENEZES, C.B.; NASCIMENTO, I. R. Inheritance of resistance to the Papaya ringspot virus-watermelon strain (PRSV-W) from watermelon accession 'PI 595201'. Crop Breeding and Applied Biotechnology, Viçosa, v. 12, n. 1, p.67-75, 2012.

BACKES, R. L.; ELIAS, H. T.; HEMP, S.; NICKNICH, W. Adaptabilidade e estabilidade de genótipos de feijoeiro no estado de Santa Catarina. Acta Scientiarum Agronomy, Maringá, v. 27, n. 2, p.309-314, 2005.

BARROS, M. M.; ARAÚJO, W. F.; NEVES, T. B. C.; CAMPOS, A. J.; TOSIN, J. M. Produção e qualidade da melancia submetida a adubação nitrogenada. Revista Brasileira de Engenharia Agrícola e Ambiental, Campina Grande v. 16, n. 10, p.1078-1084, 2012.

BOYHAN, G. E.; GRANBERRY, D. M.; TERRY KELLEY, W. Commercial watermelon production / Culture / cultivars. p. 1-5. Disponível em: http://www.agmrc.org/media/cms/B996_ B3D54FD 90A36C.pdf. Acesso em: 29 set. 2015.

CARMO, I. L. G. S.; SILVA, E. S.; MONTEIRO NETO, J. L. L.; TRASSATO, L. B.; MEDEIROS, R. D.; PORTO, D. P. Desempenho agronômico de cultivares de melancia no cerrado de Boa Vista, Roraima. Centro de Ciências Agrárias - Universidade Federal de Roraima, Boa Vista, RR. Revista Agro@mbiente, Roraima, v. 9, n. 3, p.268-274, 2015. Disponível em: http://revista.ufrr.br/agroambiente/article/view/2531/1761. Acesso em: 30 mai. 2016.

CRUZ, C. D. GENES - a software package for analysis in experimental statistics and quantitative genetics. Acta Scientiarum, Viçosa, v. 35, n. 3, p.271-276, 2013.

CRUZ, C. D.; CARNEIRO, P. C. S.; REGAZZI, A. J. Modelos biométricos aplicados ao melhoramento genético. 3. ed., v. 2. Viçosa: Ed. UFV, 2014. 668 p.

ELIAS, H. T.; SILMAR, H.; SCAPIM, C. A.; RODOVALHO, M. A.; ROYER, M. R.; MORA, F.; BARRETO, R. R. Análise da estabilidade de genótipos de feijoeiro no Estado de Santa Catarina. Acta Scientiarum Agronomy, Maringá, v. 27, n. 4, p.623-628, 2005.

Cultura Agronômica, Ilha Solteira, v.26, n.3, p.362-374, 2017 
FINLAY, K. W.; WILKINSON, G. N. The analysis of adaptation in a plant breeding programme. Australian Journal of Agricultural Research, Austrália, v. 14, n. 1, p.742-754, 1963.

GONSALVES, D.; TRIPATHI, S.; CARR, J. B.; SUZUKI, J. Y. Papaya Ringspot virus. The Plant Health Instructor. 2010. Disponível em: http://www.apsnet.org/edcenter/intropp/lessons/viruses/Pages/PapayaRingspotvirus.aspx. Acesso em: 7 out. 2016.

JIE, D.; XIE, L.; FU, X.; RAO, X.; YING, Y. Variable selection for partial least squares analysis of soluble solids content in watermelon using near-infrared diffuse transmission technique. Journal of Food Engineering, Essex, v. 118, n. 4, p.387-392, 2013.

INSTITUTO BRASILEIRO DE GEOGRAFIA E ESTATÍSTICA - IBGE. Sistema IBGE de Recuperação Automática - SIDRA 2015. Disponível em: http://www.sidra.ibge.gov.br/bda/tabela/protabl.asp?c=1612\&z=p\&o=30\&i=P. Acesso em: 05 out. 2016.

MILANEZ, G. Adensamento de plantio da melancia. 2015. Disponível em: http://www.nippo.com.br/campo/artigos/artigo448.php. Acesso em: 05 out. 2015.

NASCIMENTO, M.; CRUZ, C. D.; CAMPANA, A. C. M.; TOMAZ, R. S.; SALGADO, C. C.; FERREIRA, R P. Alteração no método centroide de avaliação da adaptabilidade genotípica, Pesquisa Agropecuária Brasileira, Brasília, v. 44, n. 3, p.263-269, 2009.

PELUZIO, J. M.; FIDELIS, R. R.; GIONGO, P.; SILVA, J. C.; CAPPELLARI, D.; BARROS, H. B. Adaptabilidade e estabilidade de cultivares de soja em quatro épocas de semeadura no sul do Estado do Tocantins. Revista Ceres, Viçosa, v. 55, n. 1, p.34- 40, 2008.

ROCHA, R. B.; MURO-ABAD, J. I.; ARAÚJO, E. F.; CRUZ, C. D. Avaliação do método centróide para estudo de adaptabilidade ao ambiente de clones de Eucalyptus grandis. Ciência Florestal, Santa Maria, v. 15, n. 3, p.255-266, 2005.

SANTOS, G. R.; CASTRO NETO, M. D.; CARVALHO, A. R. S.; FIDELIS, R. R.; AFFÉRRI, F. S. Fontes e doses de silício na severidade do crestamento gomoso e produtividade da melancia. Revista Bioscience Journal, Uberlândia, v. 26, n. 2, p.266-272, 2010.

SCOTT, A.; KNOTT, M. Cluster-analysis method for grouping means in analysis of variance. Biometrics, Washington D.C., v. 30, n. 3, p.507-512, 1974.

SILVA, J. R.; NUNES, G. H. S.; NEGREIROS, M. Z.; TORRES, J. F.; DANTAS, M. S. M. 2008. Interação genótipo x ambiente em melancia no estado do Rio Grande do Norte. Revista Caatinga, Mossoró, v. 21, n. 1, p.95-100, 2008.

TAVARES, A. T.; CHAVES, P. P. N.; AGUIAR, R. W. S.; SANTOS, M. F.; SARMENTO, R. A.; NASCIMENTO, I. R. Phenotypic response of pumpkin and melon plants to infection by simple isolates of ZYMV and mixed ZYMV+SQMV. Revista Journal of Biotechnology and Biodiversity, Gurupi, v. 5, n. 1, p.79-87, 2014.

Cultura Agronômica, Ilha Solteira, v.26, n.3, p.362-374, 2017 
VASCONCELOS, E. S.; REIS, M. S.; CRUZ, C. D.; SEDIYAMA, T.; SCAPIM, C. A. Integrated method for adaptability and phenotypic stability analysis. Acta Scientiarum Agronomy, Maringá, v. 33, n. 2, p.251-257, 2011.

VASCONCELOS, E. S.; REIS, M. S.; SEDIYAMA, T.; CRUZ, C. D. Produtividade de grãos, adaptabilidade e estabilidade de genótipos de soja de ciclos precoce e médio. Semina: Ciências Agrárias, Londrina, v. 36, n. 3, p.1203-1214, 2015.

VICENTE, D.; PINTO, R. J. B.; SCAPIM, C. A. Análise da adaptabilidade e estabilidade de linhagens elite de soja. Acta Scientiarum Agronomy, Maringá, v. 26, n. 3, p.301-307, 2004. 